\title{
Linkages between autonomy, poverty and contraceptive use in two sub-Saharan African countries
}

\author{
Samson Olusina Bamiwuye \\ Visiting Scholar, Demography and Population Studies Programme, \\ University of the Witwatersrand, South Africa, \\ Demography and Social Statistics, Obafemi Awolowo University, Ile-Ife, Nigeria.
}

Nicole De Wet

Demography and Population Studies Programme, University of the Witwatersrand, South Africa

Sunday A. Adedini

Demography and Population Studies Programme, University of the Witwatersrand, South Africa and Demography and Social Statistics, Obafemi Awolowo University, Ile-Ife, Nigeria.

\begin{abstract}
The paper presents the interaction effect of poverty-wealth status and autonomy on modern contraceptive use in Nigeria and Namibia with a view to examining whether poor women with less autonomy are less likely to use modern contraception than other women. A weighted sample of 3,45 I currently married women in 2006-07 Namibia Demographic and Health Survey (DHS) and 23,578 in 2008 Nigeria (DHS) are used in the analysis.

In Nigeria, the odds of using modern contraception is nearly 15 times higher among rich women with more autonomy than their counterparts who are poor and less autonomous, and 5.5 times higher among Namibian women. The study concluded that contraceptive behaviour of currently married women of Namibia and Nigeria are not independent of the linkage between poverty and autonomy and thus recommended that more concerted efforts be made in addressing poverty and improving the autonomous status of women in sub-Sahara Africa.
\end{abstract}

Keywords: Autonomy, poverty, contraceptive use, sub-Sahara Africa, linkages

\section{Résumé}

Cet article présente l'effet de l'interaction de l'état de pauvreté-richesse et autonomie sur l'utilisation des contraceptifs moderne au Nigeria et en Namibie en vue d'examiner si les femmes pauvres avec moins d'autonomie sont moins susceptibles de recourir à la contraception moderne que les autres femmes.

Un échantillon pondéré de 345 I femmes en 2006-07 Namibie démographique actuellement mariées et Health Survey (DHS) et 23578 en 2008 Nigeria (DHS) sont utilisées dans l'analyse.

Au Nigeria, l'impair de recours à la contraception moderne est presque 15 fois plus élevé chez les femmes riches avec plus d'autonomie que leurs homologues qui sont pauvres et sont moins autonomes et 5,5 fois plus élevé chez les femmes namibiennes. L'étude a conclu que les comportements contraception des femmes actuellement mariées de Namibie et Nigéria ne sont pas indépendants des liens entre la pauvreté et de l'autonomie et a donc recommandé que plusieurs efforts concertés être réalisés dans la lutte contre la pauvreté et l'amélioration de l'autonomie des femmes en Afrique subsaharienne.

Mots clés : autonomie, de la pauvreté, de l'utilisation des contraceptifs, Afrique subsaharienne, liens

\section{Background}

The contraceptive prevalence rate in many subSaharan African countries is still low despite the relative high knowledge and awareness of con- traception. Research literature has examined factors associated with acceptance of family planning and continuous use of contraceptive. However, in some parts of Africa, the role of 
autonomy and poverty-wealth interaction in the use of modern contraception has not been sufficiently addressed, probably due to a dearth of comparable nationally representative data. The implication is that policies and programmes directed towards increasing the use of contraceptives may not fully achieve the expected results if certain factors remain unclear.

The use of modern methods of contraception among currently married women in Nigeria declined from $9 \%$ to $8 \%$ between 1999 and 2003 (Federal Office of Statistics and ORC Macro, 2000) and slightly increased to $9.7 \%$ in 2008 (National Population Commission and ICF Macro, 2009). In contrast, evidence from the Demographic and Health Survey (DHS) in Namibia showed that modern contraceptive use increased from $26 \%$ to $43 \%$ between 1992 and 2000 , and then to $71 \%$ of all women in the 2006/2007 round of the survey (Ministry of Health and Social Services (MoHSS) [Namibia] and Macro International Inc. 2008). Despite this relative increase in Namibia, there is evidence of a high prevalence of early childbearing, especially among the poor. According to the Namibia Statistics Agency, (2012) 39\% of poorest women in the age bracket 20-24 years have had a child before age 18 and the unmet need for contraception is nearly $21 \%$. A World Bank (20II) report indicates that programmatic efforts aimed at increasing the uptake of contraception have failed to reach all segments of the population in Namibia, notably rural and poor women.

There is an upward trend in poverty incidence in Nigeria between 1980 and 1996 from $27 \%$ in 1980 to $65.6 \%$ in 1996 . The figure fell to $54.4 \%$ in 2004 and then rose again to $69.0 \%$ in 2010 (38.7\% in extreme poverty and $30.3 \%$ moderately poor) with an estimated population in poverty of over 112 million out of an estimated population of 163 million (NBS, 20I0).

Research findings from DHS in 15 countries of sub-Saharan Africa using four kinds of decisions - decisions regarding a woman's own health care, major household purchases, purchases for daily household needs and timing of visits to friends or relatives, showed the number of decisions in which women participate. Participation is extremely low in Mali, Nigeria and Burkina Faso where $76 \%, 68 \%$ and $68 \%$ of married women respectively do not have a say in any household decisions, or only in one (Vadnais et al., (2006). Namibia was not included in this analysis, because the DHS module on indicators of decision-making was included for the first time in the 2006-2007 round of survey (Ministry of Health and Social Services MoHSS) [Namibia] and Macro International Inc. 2008). Hence, there are relatively few studies on decision making autonomy in Namibia using nationally representative data.

Available literature on autonomy has concentrated on the relationship between autonomy and reproductive health, including modern contraceptives (Makinwa and Jensen, 1995; Jejeebhoy, 200 I; Basu and Koolwal, 2005; Haile and Enquesselassie, 2006; Kishor, 2005). Studies linking female autonomy and poverty to modern contraceptive use are scant. A similar study by Kishor and Johnson (2005) examines women at the nexus of poverty and violence in relation to selected reproductive health outcomes. We therefore hypothesize that poor women with less autonomy are less likely to be using contraception than other categories of women in poverty-wealth autonomy nexus.

\section{Research question/objective}

This paper aims to examine whether women at the nexus of poverty and decision making autonomy differ significantly from other women in terms of modern contraceptive use. In other words: are poor women who have low autonomy at a disadvantage in terms of contraceptive use than other women, particularly women who are also poor but have more autonomy and those who are not poor but have low autonomy?

\section{Literature review}

Studies have shown a number of factors affecting the use of contraceptives. For instance, demographic and socio-economic variables like age, education, residence, religion, age at marriage have been linked to the use of contraceptives (Odimegwu et al., 1999; Jeejehboy, 200I; Hindin 2005; Woldemical, 20II). Studies on autonomy have also used different definitions of autonomy and different dimensions of autonomy. For example, three decades ago, Dyson and Moore (1983) in a study of kinship structure, female autonomy and demographic behaviour in India defined autonomy as the ability - 
technical, social, and psychological - to obtain information and to use it as the basis for making decisions about one's private concerns and those of one's intimates. Thus in the sense of these authors, equality of autonomy between the sexes implies equal decision-making ability with regard to personal affairs.

According to Jejeebhoy, 2000 and Kishor, 2005 , the concept of autonomy simply means the control women have over their own lives the extent to which they have an equal voice with their husbands in matters affecting themselves and their families; control over material and other resources; access to knowledge and information; the authority to make independent decisions; freedom from constraints on physical mobility, and the ability to forge equitable power relationships within families.

Literature has also used the concept of autonomy and women's empowerment interchangeably, though using the same indicators (Dixon-Mueller; 2005; Jejeebhoy 2000). According to Dixon-Mueller (2000), once a woman is empowered she is presumably capable of doing things with this power that are more readily measurable than the activities that go into her acquiring the power to make her own decisions. Thus, the empowered woman is presumably the autonomous woman. In contrast, other authors have explicitly argued that autonomy is not equivalent to empowerment, stressing that autonomy implies independence whereas empowerment may well be achieved through interdependence (Malhotra and Mather, I997; Kabeer, 200I).

Kishor (1998) in a study of female autonomy among Egyptian women identified three indicators of autonomy - customary autonomy, noncustomary autonomy and realized autonomy. According to the Egypt survey, customary decision making index has to do with matters relating to children; non-customary measures other roles of women in areas of family life but not specifically concerned with children, while realized autonomy has to do with the amount of control a woman has over life relative to those of her husband and her degree of freedom of movement. Bloom et al. (20lI) examined the determinants of women's autonomy in three areas which include control over finances, decision making power and freedom of movement. Hindi (2005) uses three different variables to capture autonomy: number of decisions in which women have the final say, number of decisions in which the partner has the final say, and number of decisions in which women and partners have a joint say. Gudbradsen (2013) in his study of female autonomy and fertility employed only one of the indicators of autonomy as measured by Demographic and Health Survey - final say on visits to family and friends.

In this study, we employ the four indicators of autonomy as used by Demographic and Health Survey (2006-2007 for Namibia and 2008 DHS for Nigeria because of the complexity involved in measuring some of these dimensions (Gudbradsen, 2013).

\section{Data and method}

Two Demographic and Health Survey datasets were obtained from MEASURE DHS for these analyses: the 2006-2007 Namibia Demographic and Health Survey (DHS) and the 2008 Nigeria DHS. Both surveys are nationally representative and have comparable questions on autonomy and poverty-wealth status. In addition, knowledge of contraceptives is universal but the contraceptive prevalence rates vary.

\section{Sample size}

Weights were constructed to correct for oversampling and under-sampling and to ensure national representativeness. A weighted sample of 3,45 I currently married women in Namibia and 23,578 currently married women in Nigeria are used in the analysis.

\section{Measurement of variables}

The two explanatory variables in the study are autonomy, used interchangeably in this study as decision-making autonomy, and poverty-wealth status. Given the complexity of measuring autonomy as reported in the literature, we have selected only four dimensions of women's autonomy for which adequate information was collected in the 2008 Nigeria DHS, and 20062007 Namibia DHS. The four dimensions are: decisions regarding a woman's own health care, major household purchases, purchases for daily household needs and timing of visits to friends or relatives. According to Vadnais et al., (2006), these four dimensions of autonomy have been used to compare levels of female autonomy in thirty countries except in two where DHS data 
are available for only three out of the four household decisions.

Table 1: Percentage distribution of currently married women 15-49, with less or more autonomy by wealth quintile/wealth-poverty status and selected background characteristics

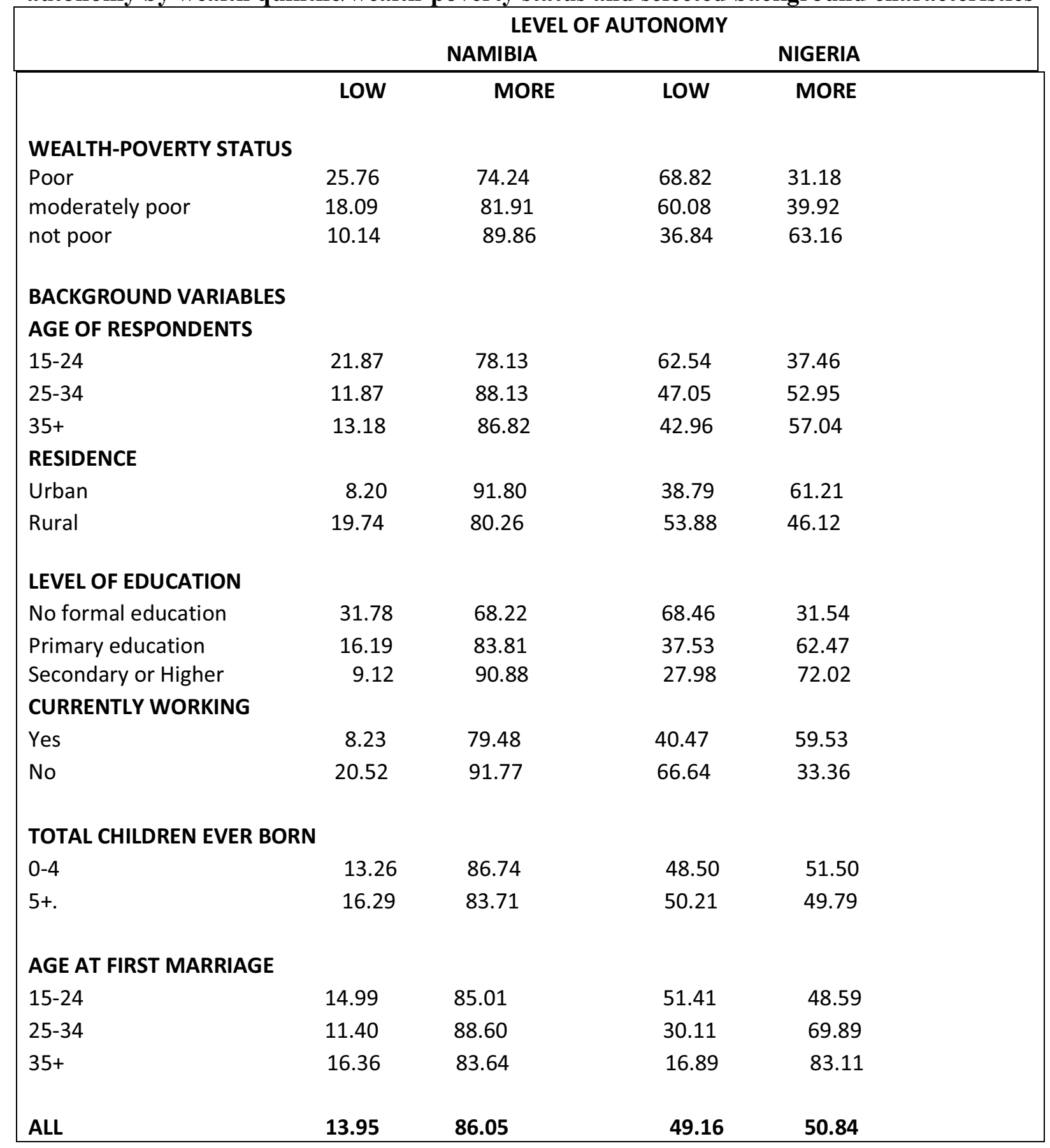

Thus in all four indicators of decision-making, an overall index (composite score) was created to reflect number of decisions in which women participate (either alone or jointly with husband). This was achieved by adding the dichotomous variables in all the four situations which produced a minimum of " 0 " and a maximum of "4". Higher score on this scale indicates a higher level of autonomy. Respondents who had scores of 0 and I were classified as having less "autonomy" and women who scored 2 to 4 were classified as having more autonomy.

Poverty-wealth status

The DHS does not collect data on direct measures of income. We estimate the poverty-wealth 
status of the households in a uniform and comparable manner using the wealth index developed by DHS and which according to Gwatkin et al., 2000, has been tested and found consistent (Rutsein, 1999) in a large number of countries with regard to inequities in household income, use of health services, and health outcomes. This wealth index is based on household ownership of consumer goods like cars, bicycles; dwelling characteristics; type of drinking water source; sanitation facilities used; roofing, and flooring. The wealth index is used in this paper as a proxy for poverty-wealth status.

\section{Outcome variable}

This paper adopts current use of any method and current use of modern method as the dependent outcomes but places the emphasis on current use of modern methods at the multivariate level of analysis. In terms of measurement and for ease of analysis, current use of any method is obtained by scoring the respondents I if they reported current use of any method, or zero otherwise. Current use of modern methods is measured by scoring respondents $I$ if they reported current use of any modern method or zero otherwise.

\section{Data analysis}

Descriptive analyses using frequency tabulations and means are done at the first level of analysis. Relationships between selected background variables and contraceptive use are examined using the Chi-Square test. Lastly, at the multivariate analysis, binary logistic regression analysis was employed because of the dichotomous nature of our outcome variable. Results of the multivariate analysis are presented in four models. The Stata 12 software was used at different levels of analysis.

\section{Results}

\section{Relationship between autonomy and poverty-wealth status and selected background characteristics}

The overall picture of level of autonomy shows that fourteen percent of currently married Namibian women have low autonomy compared with nearly half (49.2\%) of currently married women in Nigeria. Women in the first quintile (poorest) are likely to have less auton- omy than women in higher quintiles in both countries. Higher levels of wealth status are thus positively associated with more autonomy. There is no consistent relationship between age of women and autonomy for Namibia and Nigeria. While autonomy rises by age for currently married women in Nigeria, it is not so for Namibia.

The relationships between autonomy and other background characteristics like place of residence, education, employment status, children ever born and age at marriage are consistent in both countries. For example, women in urban areas are more autonomous than those in the rural areas; level of autonomy increases significantly by increase in education; women who are currently working are significantly more likely to have more autonomy than those not currently working; and higher fertility as measured by number of children ever born is associated with lower autonomy. As regards age at first marriage, women who married in the middle age group (25-34) are more autonomous than those who married at the younger age (below 25 ) or at a latter age (35 years or more).

\section{Relationship between current contraceptive use by autonomy, poverty-wealth status and selected background characteristics}

Current use of any contraception or any modern method varies with residence, education, number of living children, number of children ever born and poverty-wealth status and level of autonomy. Current use of modern contraceptives is at its peak among women in the age group 25-34 for Namibia (55.9\%) and for Nigeria (26.9\%), and the least for women below age 25 in Namibia (48.6\%) and their counterparts in Nigeria (14.4\%).

As expected, current use of contraceptives is higher in both countries among the urban women than the rural, irrespective of the type (any method or modern method). For Namibia, current use of modern methods increases from $31.5 \%$ among women with no formal education to $62.6 \%$ among those who have completed secondary school or more. Among currently married women in Nigeria, contraceptive prevalence (modern) is at its peak among those with secondary education or more $(13.8 \%)$ and the least $(2.6 \%)$ among women with no formal education. Currently married women who are cur- 
rently working are more likely to use contraceptives in Namibia and Nigeria.

Table 2: Percentage of currently married women, 15-49 who currently used any method of contraceptives, who currently used modern method of contraceptive by explanatory variables and selected background characteristics

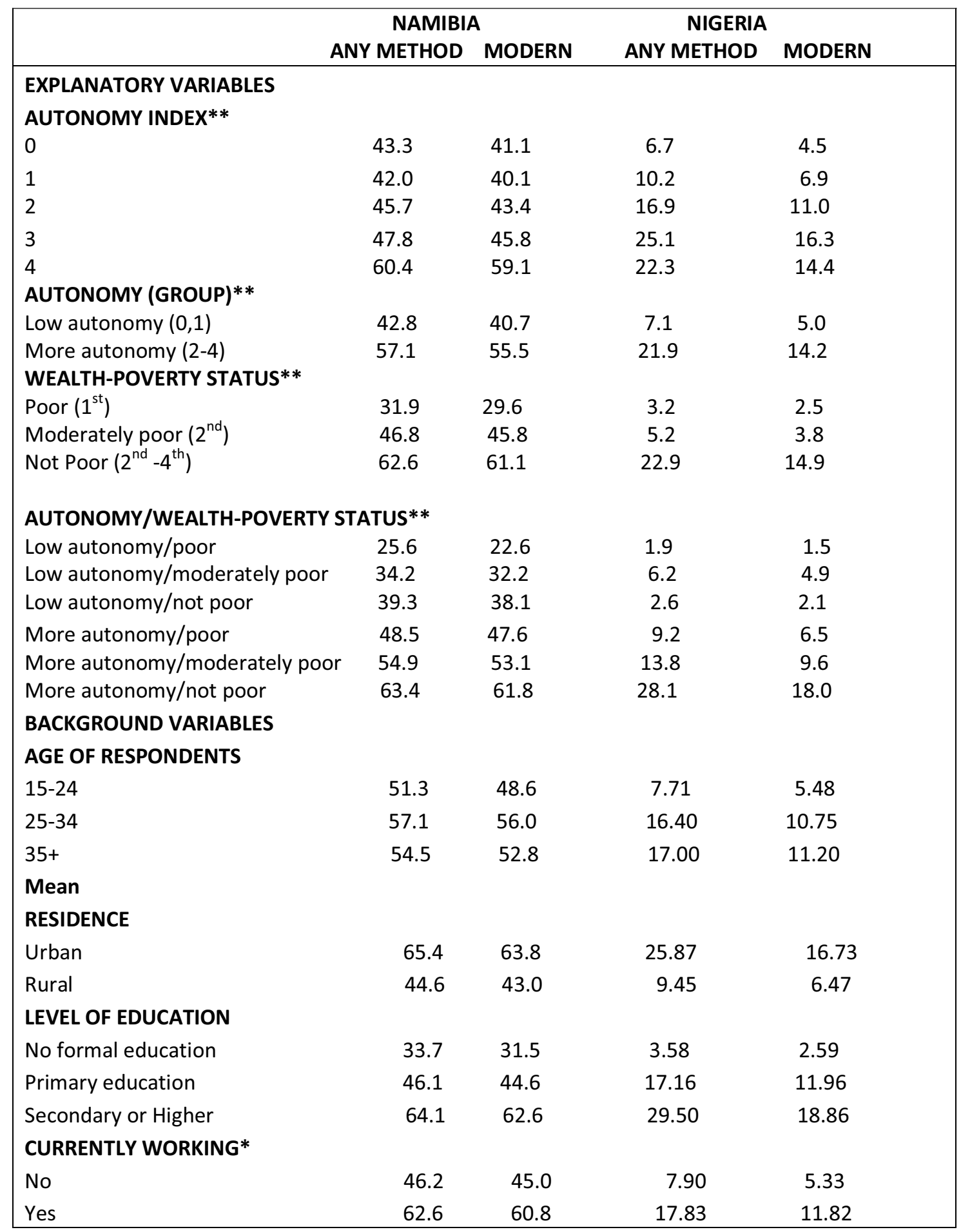

The proportion of currently married Namibian women who married before age 25 and who are currently using contraceptives is almost the same with those who married in age bracket 25 -
35 for any method and for modern methods. However, the percentage of currently married in Nigeria in age group $25-34$ who are currently using any method of contraceptive is nearly 
twice those below age 25. Modern use of contraceptives is at its peak (15.2\%) among currently married women whose age at first marriage falls in the middle age group.

High autonomy is associated with an increase in current use of contraception in Namibia and Nigeria. Currently married women with more autonomy are almost three times more likely to be using contraceptives in Nigeria. Two-fifths of Namibian women who are currently married and who have less autonomy are currently using any method of contraception $(40.7 \%)$ and any modern method (42.8\%). This is compared with $55.5 \%$ of those who have more autonomy and who are currently using modern contraceptives and $57.1 \%$ of women who are more autonomous and who are currently using any form of contraception.

In Namibia, currently married women who are poor and who have less autonomy are the least likely to use contraceptive methods (25.6 percent for any method and 22.6 percent for modern methods) and highest among rich women and who have more autonomy (63.4 percent for any method and 61.8 percent for modern methods). This picture is similar when compared with Nigeria where variations in contraceptive use by levels of poverty-wealth/ autonomy interaction is at its peak among rich women with more autonomy $(18.0 \%$ for modern and $28.1 \%$ for any method) and where poor women with less autonomy are the least likely to be currently using contraceptives (I.5 percent for modern and $1.9 \%$ for any method).

\section{Multivariate analysis}

Table 3 presents odds ratio estimates from logistic regression analysis models of current contraceptive use among currently married women by selected variables. The first two models examine the individual effect of the principal explanatory variables - wealth-poverty status and autonomy level, while model three combines the two explanatory variables. The third model relates the interaction between autonomy and wealth-poverty to the outcome variable.

In the first model, the odds of using current use of modern contraception increases by level of autonomy in both countries. In Namibia, for example, currently married women aged 15-49 who are more autonomous are 1.8 times more likely to use modern methods than other women with less autonomy. The odds of using modern methods is greater among Nigerian women with more autonomy, who are more than 3 times likely to use a modern method than those with less autonomy. In the second model, the odds of currently using any modern method also rises as the wealth-poverty status increases in both countries. In Namibia, for example, currently married women aged 15-49 who are moderately poor are 1.5 times more likely to use modern contraception than those who are poor. Currently married women who are not poor are roughly 7 times more likely to use modern methods than those who are poor.

Moderately poor women and those who are not poor are 2 times and 3.7 times respectively more likely to use modern contraception than their counterparts who are poor, suggesting a significant positive relationship between wealthpoverty status and contraceptive use.@@@

In the model that incorporates the effect of two explanatory variables, women with more autonomy remain significantly more likely to use modern methods than those with less autonomy in both countries (Namibia, OR=2.27; Nigeria, odd $=1.95 ; p<0.001)$. Similarly, poverty-wealth status still emerges as a significant predictor of contraceptive use. For example, while in Namibia, moderately poor women and rich women (not poor) are significantly more likely to be using contraceptives (odds for moderately poor =1.95; odds for rich =3.49), currently married women in Nigeria who are moderately poor are 1.43 times more likely to be using modern methods while the non-poor are 5.3 times more likely to be using a modern method.

In model 4, an attempt is made to examine the interaction effects of different levels of autonomy and different levels of poverty-wealth status on current use of modern contraceptives among currently married women. This is to enable us to provide answers to our major research question on whether women at the nexus of poverty and autonomy differ significantly from other women in terms of modern contraceptive use.

In Namibia, poor women with less autonomy are significantly less likely to be using modern contraceptives than all other categories of women. The result consistently shows that the higher the poverty-wealth status the more likely 
women will be using modern contraceptives with those with more autonomy faring better.

Rich women in Nigeria who are more autonomous are nearly 15 times more likely to be using modern contraception than their counter- parts who are poor and are less autonomous. Among Namibian women who are rich and have more autonomy the odds of using modern methods of contraception are 5.5; a value much lower than their Nigerian counterparts.

Table 3: Logistic Regression Analysis of Likelihood of Current Use Of Modern Contraception among Currently Married Women 15-49 DHS -Nigeria (2008) and Namibia DHS 2006-7

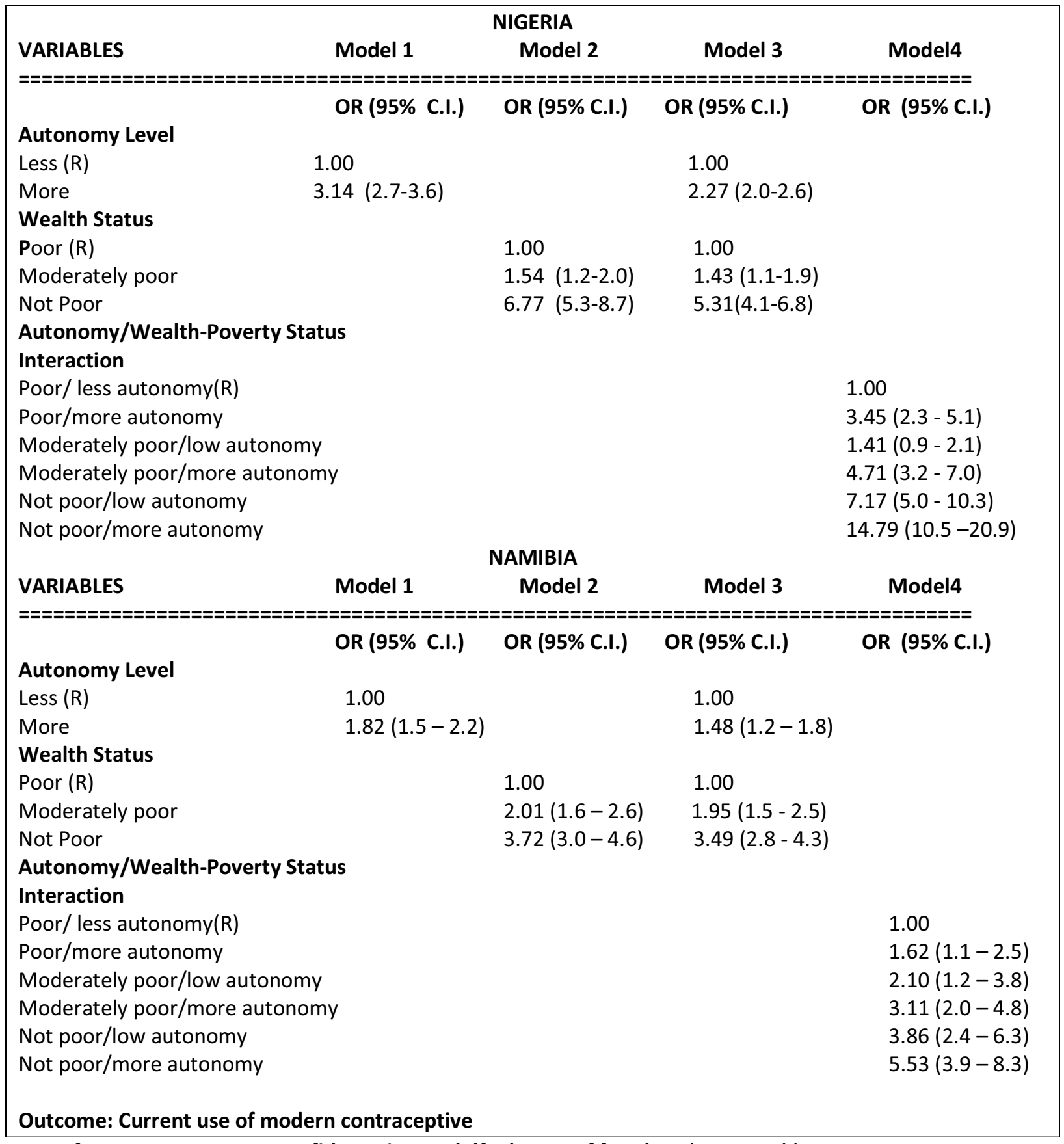

$\mathbf{R}=$ Reference category $\mathrm{Cl}=$ Confidence interval $\mathrm{df}=$ degree of freedom ${ }^{*} \mathrm{P}<0.05 * * \mathrm{p}<0.01$ Source : Authors' computation; Nigeria DHS, 2008 and Namibia DHS (2006-07) and 


\section{Discussions}

Our main research question is how the interaction between poverty-wealth status and autonomy affect current use of contraceptive. Hence, currently married women who are poor and who have low autonomy are compared with other categories of women in terms of current use of contraceptives.

In Namibia, currently married women who are poor and who have less autonomy are the least likely to use modern contraception. This picture is similar to data from 2008 DHS for Nigeria where variations in contraceptive use by levels of poverty-wealth /autonomy interaction is at a peak among rich women with more autonomy and where poor women with less autonomy are the least likely to be currently using contraceptives. Thus, currently married women who are poor and who have less autonomy are more disadvantaged in terms of contraceptive use than other categories of women. The result of the multivariate analysis further confirms those of bivariate analysis above, with respect to how poverty-wealth status, autonomy and interaction between autonomy and poverty-wealth status relate to current use of modern contraceptives in Namibia and Nigeria.

In comparing contraceptive prevalence rates between the countries, it is obvious that Namibia is far ahead of Nigeria. This may not be unconnected with improved women status and relatively lower number of people living below the poverty line in Namibia than Nigeria. For example, $34 \%$ of Namibians live on US\$I per day and $55.8 \%$ on US\$2 per day (PRB, 20II) while in 2009/2010, $28.7 \%$ of the Namibian population lived below the poverty line showing a downward trend in poverty line (Namibia Statistics Agency, 20I2). In Nigeria, poverty incidence rose from $27 \%$ in 1980 to $69 \%$ in 2010 with $61.2 \%$ living on US\$I per day in 2010, using the old World Bank standard (NBS, 20I2).

\section{Conclusion and policy recommendation}

The study concluded that the contraceptive behaviour of currently married women in Namibia and Nigeria are not independent of the linkage between poverty and autonomy. Thus independent effects of autonomy, wealth-poverty status and socio-demographic factors may not provide enough explanations of the deter- minants of contraceptive use among currently married women in sub-Saharan Africa. This is because of the salient role inter-linkage between autonomy and wealth-poverty status plays in explaining differences in contraceptive usage.

Although this study has its limitations in terms of making any causal inference because of the cross-sectional nature of the data, policy and programmes aimed at increasing contraceptive use in sub-Saharan Africa should not take for granted the link between poverty-wealth status and autonomy. The study therefore recommends that more concerted efforts should be made in addressing poverty and improving the autonomous status of women.

\section{Acknowledgements}

The authors would like to acknowledge the Demography and Population Studies Programme of the University of the Witwatersrand for providing an enabling environment to carry out this study through her Visiting Research Fellowship Programme. Our sincere and deepest gratitude goes to Professor Clifford Odimegwu for his mentorship and prompt guidance, and to Julia Mamabolo for her promptness in printing drafts of data analysis results and manuscripts. Lastly the authors are grateful to ICF Macro International and MEASURE DHS for the release of the datasets used in this study.

Authors' contributions: All the authors contributed significantly to the article. Bamiwuye conceived the topic, analyzed the data and participated in the report writing; Adedini reviewed the literature and participated in report writing; De Wet participated in report writing and editing. The authors have no conflict of interest

\section{References}

Basu, A.M. and Koolwal, G.B. 2005. "Two Concepts of Female Empowerment: Some Leads from DHS Data on Women's Status and Reproductive Health" in Kishor, Sunita, Ed. 2005. A Focus on Gender: Collected Papers on Gender Using DHS Data. Calverton, Maryland, USA: ORC Macro.

Bloom, S.S., Wypij, D. and Das Gupta, M. (200I) Dimension of Women's Autonomy and the Influence on Maternal Health Care Utilization in a North Indian city. Demography 28 (I): 67-78

Dyson, T. and Moore, T (1983). On Kinship Structure, Female Autonomy, and Demographic Behavior in India. Population and Development 
Review 9(I): 35-54

Federal Office of Statistics,Nigeria and ORC Macro, 2000: Nigeria Demographic and Health Survey, 1999

Gwatkin, D.R., Rutstein, S. Johnson, K., Pande, P.; and Wagstaff, A. (2000). "Socio-economic Differences in Health, Nutrition and Poverty". HNP/Poverty Thematic Group of the World Bank, Washington, D.C.: The World Bank.

Gudbradsen, N.H. (20I3). Female Autonomy and Fertility in Nepal. South Asia Economic Journal. http://sae.sagepub.com/content/ I4/ I/ 157.refs.html, accessed on May I5, 2013

Haile, A ; Enqueselassie, F. 2006 Influence of women's autonomy on couple's contraception use in Jimma town, Ethiopia. Ethiopian Journal of Health Development. 20(3)

Hindin, M.J.(2005): Women's Autonomy, Status, and Nutrition in Zimbabwe, Zambia, and Malawi. In

Kishor, Sunita, Ed. 2005. A Focus on Gender: Collected Papers on Gender Using DHS Data. Calverton, Maryland, USA: ORC Macro.

Jejeebhoy, S.J. (2000). Women's Autonomy in Rural India: Its Dimensions, Determinants, and the Influence of Context. In Women's Empowerment and Demographic Processes: Moving beyond Cairo, ed.H. Presser and G. Sen. New York: Oxford University Press.

(200I). "Women's Autonomy and

Reproductive Behaviour in India," in Zeba Ayesha Sathar and James F. Phillips (eds.), Fertility Transition in South Asia. Oxford: Oxford University Press.

Kabeer, N. (200I). Reflections on the measurement of women's empowerment: In Discussing

Jejeebhoy, S.J. 1995 Women's education, autonomy, and reproductive behaviour: Experience from developing countries. Oxford: Clarendon Press.

Kishor S (1998), Autonomy and Egyptian women: findings from the 1988 Egypt Demographic and Health Survey. Calverton, MD: Macro International, Demographic and Health Surveys (DHS), (Occasional Papers 2) (2000). Empowerment of women in Egypt and links to the survival and health of their infants. In Women's empowerment and demographic processes: Moving beyond Cairo, ed. H. Presser and G. Sen. New York: Oxford University Press.

Kishor, S. and Johnson K. (2005): "Women at the nexus of poverty and violence: how unique is their disadvantage?" In Kishor, Sunita, Ed. 2005. A Focus on Gender: Collected Papers on Gender Using DHS Data. Calverton, Maryland, USA: ORC Macro.

Makinwa P. and Jensen A.(1995) (eds.) Women's position and demographic changes in sub-Saharan Africa. IUSSP, Liege, Belgique

Malhotra, A. and Mather, M. (1997): Do schooling and work empower women in developing countries? The case of Sri Lanka. Sociological Forum 12(4): 599-630.

Namibia Statistics Agency (20I2): Poverty Dynamics in Namibia: A comparative study using 1993/94, 2003/04 and the 2009/I0 NHIES Surveys.

National Population Commission and ICF Macro (2009): Nigeria Demographic and Health Survey 2008. Abuja, Nigeria: National Population Commission and ICF Macro.

Odimegwu C.O, 1999 Family planning attitudes and use in Nigeria: A factor analysis. International Family Planning Perspectives, 25(2):86-9I.

PRB (20I I) World Population Data Sheet

Rutstein, S. (1999): Wealth versus expenditure: Comparison between the DHS wealth index and household expenditures in four departments of Guatemala. Unpublished.

Vadnais, D., Kols, A., Abderrhahim , N (2006): Women's Lives and Experiences: Changes in the in the Past Ten Years. Research Findings from the Demographic and Health Surveys. ORC Macro, Calverton, Maryland, USA

Woldemicael, G. (20I I): Currently married women with an unmet need for contraception in Eritrea: Profile and determinants. Canadian Studies in Population 38, No. I-2 (Spring/Summer 20I I):6I 81 .

World Bank(20I I): Reproductive Health at a Glance in Namibia.www.worldbank.org/population accessed on $21 / 05 / 2013$. 